\title{
PELATIHAN PERWASITAN DASAR BOLA VOLI BAGI MAHASISWA PJKR STKIP CITRA BAKTI DALAM KEGIATAN TURNAMEN BOLA VOLI ANTAR PELAJAR SE-KABUPATEN NGADA DAN NAGEKEO
}

\author{
Yanuarius Ricardus Natal'), Bernabas Wani' ${ }^{2}$, Nikodemus Bate ${ }^{3)}$ \\ 1,2,3) Pendidikan Jasmani Kesehatan dan Rekreasi \\ ${ }^{1,2,3)}$ Sekolah Tinggi Keguruan dan IImu Pendidikan Citra Bakti \\ 1)yanuariusrichardus@gmail.com ${ }^{2)}$ bernabas.wani@gmail.com ${ }^{3)}$ nico.dua21@gmail.com
}

\begin{abstract}
Histori artikel
Received:

15 Maret 2020

Accepted:

12 April 2020

Published:

15 April 2020

Abstrak

Pengabdian kepada masyarakat ini dilatar belakangi oleh permasalahan yang dialami oleh mahasiswa PJKR khususnya pada semester V dan VII yakni 1)terbatasnya pemahaman tentang dasar perwasitan bola voli, 2) kurangnya keterampilan dalam memimimpin pertandingan bola voli berdasarkan aturanaturan resmi dari induk organisasi persatuan bola voli seluruh Indonesia. Tujuan dilaksanakannya pengabdian ini adalah memberikan dasar-dasar perwasitan bola voli serta keterampilan dalam memimpin pertandingan bola voli dengan menerapkan peraturan resmi dari persatuan bola voli seluruh Indonesia melalui turnamen bola voli antar pelajar se-kabupaten Ngada dan Nagekeo tahun 2020. Metode dalam pengabdian ini yaitu metode teori, dimana setiap peserta pelatihan diberikan materi dalam bentuk power point, ceramah, dan tanya jawab serta metode praktik yakni setiap peserta mempraktekkan secara langsung menjadi wasit utama, wasit dua, hakim garis, dan scoorer sheet. Hasil dari kegiatan pelatihan perwasitan dasar bola voli bagi mahasiswa pendidikan jasmani kesehatan dan rekreasi yakni : 1) Setiap peserta yang merupakan mahasiswa semester V dan VII telah berhasil menguasai dasar-dasar perwasitan bola voli, 2) Para peserta pula telah mengaplikasikan keterampilan memimpin pertandingan bola voli dengan mengacu pada peraturanperaturan resmi dari induk organisasi persatuan bola voli seluruh Indonesia dalam turnamen antar pelajar se-kabupaten Ngada dan Nagekeo. 3) Mahasiswa dari semester V dan VII merasa senang dan tertarik untuk menggeluti bidang perwasitan bola voli ini.
\end{abstract}

Kata-kata Kunci : perwasitan dasar, turnamen bola voli 
Abstract. This community service is motivated by problems experienced by PJKR students, especially in semester V and VII namely 1) limited understanding of volleyball arbitration bases, 2) lack of skills in leading volleyball matches based on official rules from the parent volleyball union organization throughout Indonesia. The aim of this service is to provide the basics of volleyball arbitration as well as the skills in leading volleyball matches by applying official regulations of volleyball unions throughout Indonesia through volleyball tournaments between students in Ngada and Nagekeo districts in 2020. The method in this service is the theoretical method, where each training participant is given material in the form of power points, lectures, and questions and answers as well as practical methods where each participant practices directly as the main referee, second referee, and line judge. Results from basic training activities volleyball for health and recreation physical education students namely: 1)Every participant who is a student of semester V and VII has successfully mastered the basics of volleyball arbitration, 2) The participants have also applied the skills to lead the volleyball match by referring to the rules officially from the parent organization of the volleyball union throughout Indonesia in tournaments between students throughout the Ngada and Nagekeo districts. 3) Students from semester V and VII feel happy and interested to work in the field of volleyball arbitration.

Key Words: basic referee, volleyball tournament.

\section{PENDAHULUAN}

Fenomena berolahraga belakangan ini telah menjadi magnet yang tidak dapat terpisahkan dalam kehidupan masyarakat sehari-hari. Aktifitas olahraga telah menjadi salah satu kebutuhan primer di kalangan masyarakat luas saat ini, sehingga masing-masing individu selalu berpikir untuk meluangkan waktu guna melaksanakan aktifitas ini ditengah kesibukannya sehari-hari (Sumaryanto, 2012:15). Berbagai kemajuan pembangunan melalui aktivitas-aktivitas di bidang keolahragaan akan bermuara pada meningkatnya budaya dan prestasi olahraga (Natal, 2018:16). Gerakan memasyarakatkan olahraga dan mengolahragakan masyarakat di Indonesia (sport for all) telah menunjukkan kemajuan, paling tidak ditinjau dari animo masyarakat yang berolahraga. Ada beberapa alasan mengapa warga masyarakat berpartisipasi dalam aneka aktivitas jasmani atau "olahraga masyarakat". Pertama, semakin disadari pentingnya pengisian waktu senggang dengan kegiatan positif, termasuk olahraga yang relatif murah dan dapat memenuhi penyaluran hobi. Kedua, semakin disadari pentingnya kesehatan dan kebugaran jasmani beserta keuntungannya untuk mencapai kualitas hidup sejahtera paripurna. Aktivitas jasmani pada umumnya atau kegiatan olahraga pada khususnya merupakan salah satu bentuk sosialisasi diri dalam bentuk aktifitas jasmani, sehingga menimbulkan kegairahan tersendiri bagi setiap pelakunya. Berbagai macam tujuan orang berolahraga salah satunya berkaitan dengan pencapaian suatu prestasi yang menuntut setiap pelaku untuk terus meningkatkan kualitas dirinya melalui keterlibatan penuh dalam setiap aktivitas olahraga baik dalam sebuah pertandingan perorangan maupun beregu atau tim tentunya. Salah satu wadah pengembangan prestasi di bidang olahraga salah satunya adalah melalui permainan atau olahraga bola voli. Bola voli merupakan salah satu jenis olahraga yang dimainkan oleh dua tim di sebuah arena permainan yang dipisahkan oleh sebuah net. Tujuan permainan itu 
sendiri adalah melewatkan bola diatas net agar dapat jatuh menyentuh lantai di wilayah lapangan lawan (PP PBVSI, $2017: 1-6)$.

Bola voli merupakan salah satu olahraga di dunia yang paling berhasil, popular, penuh persaingan sekaligus menyenangkan. Gerakan-gerakannya cepat, menegangkan dan seru, sehinga dibutuhkan keseriusan dalam berlatih maupun pada saat bertanding (Alexander, 2013 : 5-6). Tidak terlepas pula bahwa tingkat rivalitas tim ketika bertanding sangat agresif, sehingga dibutuhkan seorang pengadil lapangan pertandingan yang benar-benar mampu memimpin dengan semangat profesionalitas. Tugas seorang wasit yakni memimpin jalannya pertandingan agar dapat berjalan lancar, sehingga dalam mengambil keputusan wajib memmiliki sikap netral dan objektif, selain itu juga merupakan sarana dalam menyebarluaskan peraturan permainan bola voli ini kepada masyarakat. Berdasarkan pengabdian terdahulu penulis tentang Pendampingan Penyelenggaraan Pertandingan Bola Voli Holy Spirit Youth Day OMK se-Paroki Roh Kudus Mataloko Kelurahan Todabelu Tahun 2019 yang terpublis pada media Ekora NTT, (ekorantt.com, 9 Juli 2019) menjelaskan bahwa kehadiran perangkat pertandingan yang dalam hal ini adalah seorang wasit yang profesional di rasa mampu untuk mendukung dan menjamin terselenggaranya suatu kegiatan atau pertandingan olahraga. Kehadiran wasit yang profesional sungguh dirasakan dampaknya dalam turnemen tersebut, sehingga tidak adanya protes dan pertikaian dari setiap tim akibat dari keberpihakkan oleh seorang wasit.

Berdasarkan kenyataan di atas, pengabdi merasa perlu untuk memberikan sebuah pendampingan berupa pelatihan perwasitan dasar bola voli bagi mahasiswa program studi PJKR STKIP Citra Bakti dalam kegiatan turnamen bola voli antar pelajar yang bertujuan untuk memberikan pemahaman akan dasar-dasar mewasiti dan keterampilan memimpin pertandingan bola voli bagi mahasiswa program studi PJKR, yang kelak bukan hanya menjadi seorang guru tetapi bisa juga menjadi sebagai seorang wasit yang profesional di bidangnya. Pelatihan ini selain dibekali dengan sajian materi, mahasiswa ini pula diberikan langsung dengan kesempatan untuk tampil menjadi seorang wasit 1 , wasit 2, linesman dan juga scoresheet.

\section{METODE PELAKSANAAN}

Metode yang digunakan tim pengabdi pada kegiatan pengabdian masyarakat yakni melalui dua tahapan. Tahapan yang pertama yakni peserta dikelompokan ke dalam sebuah tim kemudian diberikan materi-materi tentang dasar-dasar mewasiti dan peraturan-peraturan dasar olahraga bola voli dengan berdasarkan pedoman peraturan resmi bola voli yang dikeluarkan oleh induk organisasi yakni PBVSI untuk diimplementasikan sejak tahun 2007 sampai 2020 dalam bentuk ceramah dan demonstrasi dan diskusi. Selanjutnya setiap peserta akan mendemonstrasikan keterampilan memimpin sebuah pertandingan secara 
bergilir lalu diberikan kesempatan kepada setiap peserta untuk memeberikan kritikan dan masukan yang selanjutnya diberikan kesimpulan akhir oleh pengabdi. Tahapan kedua untuk setiap peserta kegiatan melebur menjadi wasit dalam turnamen bola voli PJKR Citra Bakti Cup I yang kemudian memimpin dan menerapakan atauran permaian yang sesuai dengan aturan resmi PBVSI seraya mensosialisasikan aturan-aturan tersebut dalam setiap pertandingan. Peserta yang menjadi sasaran dalam kegiatan pengabdian masyarakat ini adalah mahasiswa semester V (lima) dan VII (tujuh) yang sudah terlebih dahulu lulus program mata kuliah bola voli lanjutan, dengan total mahasiswa peserta kegiatan sejumlah 40 orang dengan lama pelaksanaan kegiatan selama satu minggu yang terbagi atas 2 hari kegiatan teori dan 5 hari kegiatan praktek di lapangan.

\section{HASIL DAN PEMBAHASAN}

\section{Hasil}

Adapun hasil dari kegiatan pelatihan perwasitan dasar bola voli bagi mahasiswa program studi PJKR STKIP Citra Bakti Ngada semester V dan VII dalam kegiatan turnamen bola voli antar pelajar se-kabupaten Ngada dan Nagekeo tahun 2020, dapat dijelaskan yakni setiap peserta kegiatan yaitu mahasiswa semester V dan semester VII sangat antusias dan menerima tim pengabdi yang membawakan materi perwasitan bola voli dasar selama 2 hari teori dan 5 hari praktek memimpin di lapangan, hal ini dibuktikan dengan partisipasi aktif peserta dalam kegiatan pelatihan bola voli yang mampu menerima masukan selama kegiatan pelatihan berlangsung. Para peserta kegiatan pelatihan ini pula mengalami peningkatan kemampuan dan pemahaman perwasitan dasar bola voli serta telah mengaplikasikan keterampilan memimpin pertandingan bola voli dengan mengacu pada peraturan-peraturan resmi dari induk organisasi persatuan bola voli seluruh Indonesia dalam turnamen antar pelajar se-kabupaten Ngada dan Nagekeo sehingga pada turnamen tersebut keseluruhan pertandingannya dapat berjalan lancar tanpa adanya protes sebagai akibat dari kesalahan mengambil keputusan dari para wasit tersebut dan adanya pengatahuan baru yang diperoleh peserta kegiatan pelatihan ini, sehingga mahasiswa dari semester V dan VII merasa senang dan tertarik untuk menggeluti bidang perwasitan bola voli.

\section{Pembahasan}

Wasit dalam pertandingan bola voli tidak dapat dipisahkan keberadaan serta peran sentralnya dari permainan bola voli itu sendiri. Hal ini yang menjadikan peranan wasit sebagai penengah antara dua tim yang sedang bertanding dalam penegakkan aturan dan norma yang ada serta untuk menciptakan pertandingan yang fair play. Permainan bola voli yang diperagakan oleh ke dua tim pada saat pertandingan berlangsung menjadi bahan pengamatan utama dari wasit. Wasit akan memulai dan menghentikan pertandingan dengan sinyal-sinyal. Sinyal yang diberikan oleh wasit dapat berasal dari bunyi peluit, bahasa verbal, 
tanda-tanda atau simbol dari bahasa tangan, atau bahkan menggunakan kartu. Dalam peraturan bola voli (PP PBVSI, 2017: 78-83) ada 25 isyarat tangan untuk wasit dan isyarat bendera untuk hakim garis. Wasit harus sedapat mungkin menghafal dan dapat menerapkan sesuai dengan kesalahan yang ada di lapangan. Untuk itu diperlukan latihan berulang-ulang dalam jangka waktu yang lama, sehingga pada pelatihan ini pengabdi meringkas beberapa aturan wajib yang harus dikuasai oleh wasit dasar bola voli tersebut. Ini tentunya menjadi tantangan tersendiri dari setiap peserta untuk terus mengasah kemampuan memahami aturan dasar wasit bola voli serta kemampuan lebih dalam mengaplikasikan ke dalam sebuah keterampilan memimpin pertandingan resmi. Proses pelatihan yang dilaksanakan selama 2 hari dengan materi teori selama 6 jam serta 5 hari dengan praktek lapangan memimpin pertandingan dengan total jam 10 merupakan salah satu upaya yang dilakukan oleh tim pengabdi untuk memberikan pemahaman lebih kepada setiap peserta pelatihan yang merupakan mahasiswa/i semester lima dan tujuh yang juga sebentar lagi akan menjadi calon guru penjas untuk mendalami setiap sesi pelatihan ini dengan baik. Wasit menjadi bagian dari sebuah permainan yang terintegrasi ke dalam sebuah event atau turnamen. Hakekat dari sportifnya sebuah turnamen terletak pada konsep keadilan dan konsisten seorang wasit yaitu: bersikap adil kepada semua peserta dan dipandang adil oleh penonton. Kedua elemen itu membutuhkan kepercayaan tinggi agar pemain bisa bermain dengan baik, maka seorang wasit haruslah bersikap akurat dalam melakukan keputusan atas kesalahan atas apa yang telah dilakukan setiap pemain dalam sebuah tim yang bertanding saat itu. Jadi, kita bisa mengatakan bahwa seorang wasit yang baik akan menggunakan aturan untuk membuat kompetisi menjadi pengalaman yang memuaskan bagi dirinya sendiri serta bagi para penikmat pertandingan itu sendiri baik official tim, para pemain, suporter maupun para penonton tentunya (PP PBVSI, 2017 : 85-87).

Dalam kegiatan pelatihan perwasitan bola voli dasar ini termanifestasi pula dengan bentuk pengaplikasian keterampilan memimpin pertandingan resmi bola voli, sehingga untuk menunjang pemahaman dari setiap peserta dilakukan dua cara yakni pemberian materi teori dan praktek langsung di lapangan. Materi teori dilakukan dengan berbagai cara yakni penyajian konsep yang merupakan cara penyampaian informasi/pengetahuan tentang arti serta bentuk menginterpretasikan peraturan perwasitan dasar bola voli di dalam lapangan dengan menyampaikan beberapa pengalaman atau kejadian empiris yang pernah terjadi, sehingga mudah untuk dipahami para peserta dengan baik, selain itu adalah diskusi yang merupakan bentuk komunikasi antara setiap peserta yang dibagi ke dalam kelompokkelompok untuk membahas suatu topik yang merupakan salah satu ilmu atau pengetahuan dasar tentang bola voli. Setelah dilaksanakan penyajian konsep dan diskusi tentang berbagai permasalahan yang ada, selanjutnya setiap peserta pelatihan ini mempraktekkan secara langsung di lapangan bola voli STKIP Citra Bakti. Setiap peserta 
akan mengambil bagian secara terkontrol dan bergantian untuk menjadi bagian dalam perangkat pertandingan bola voli antar pelajar SMA di wilayah kabupaten Ngada dan Nagekeo yang terbagi atas 4 pool untuk kategori pria dan wanita (PP PBVSI, 2017 : 69-71).

Suharsimi Arikunto (2010:16-19) menjelaskan bahwa sebuah di akhir kegiatan penting untuk dilaksanakannya sebuah evaluasi. Hal ini bertujuan untuk memberikan dampak efektivitas serta produktivitas, baik itu dalam lingkup individu, kelompok terhadap sebuah pelaksanaan program kegiatan. Pada pelatihan perwasitan dasar bola voli bagi mahasiswa program studi pendidikan jasmani kesehatan dan rekreasi STKIP Citra Bakti semester V dan VII dalam kegiatan turnamen bola voli antar pelajar se-kabupaten Ngada dan Nagekeo tahun 2020 juga melaksanakan mekanisme evaluasi. Evaluasi yang dilakukan oleh pengabdi dalam bentuk teori dengan menggunakan tes tulis pilihan ganda dengan jumlah soal 20 , dengan lima opsi pilihan a,b,c,d dan e. Sedangkan untuk praktek lapangan menggunakan pengamatan oleh tim pengabdi kepada setiap peserta pelatihan dalam mewasiti pertandingan setengah set. Bentuk materi pengamatan akan meliputi: a). ketegaran dalam menghadapi tim, b).ketegasan dalam meniup peluit. c). Ketepatan waktu dalam meniup peluit. d). Urutan dalam meniup peluit bola mati, menunjuk, servis dan isyarat kesalahan. e). Keluwesan dalam memberi isyarat. f). Ketepatan dalam memberi isyarat. (PP PBVSI, 2017: 28). Dari hasil evaluasi kegiatan pelatihan perwasitan dasar bola voli di atas menunjukkan bahwa setiap peserta telah berhasil menguasai materi teori dan praktek dengan baik.

\section{KESIMPULAN}

Dari hasil kegiatan pengabdian pelatihan perwasitan dasar bola voli bagi mahasiswa program studi pendidikan jasmani kesehatan dan rekreasi STKIP Citra Bakti semester V dan VII dalam kegiatan turnamen bola voli antar pelajar se-kabupaten Ngada dan Nagekeo tahun 2020, dapat ditarik kesimpulan bahwa setiap peserta yang merupakan mahasiswa semester $\mathrm{V}$ dan VII telah berhasil menguasai dasar-dasar perwasitan bola voli dengan mampu mengaplikasikan keterampilan memimpin pertandingan bola voli dengan mengacu pada peraturan-peraturan resmi dari induk organisasi persatuan bola voli seluruh Indonesia dalam turnamen antar pelajar se-kabupaten Ngada dan Nagekeo, sehingga para mahasiswa dari semester V dan VII merasa senang dan tertarik untuk menggeluti bidang perwasitan bola voli ini.

\section{DAFTAR PUSTAKA}

Alexander, M. (2013). An Analysis of The Volleyball Jump Serve. Kanada : Sport Biomechanics Lab University of Manitoba.

Arikunto, Suharsimi. (2010). Evaluasi Program Pendidikan: Edisi 2. Jakarta: Bumi Aksara

Donofan, Gordi. (2019, 3 November). Dosen Prodi PJKR STKIP Citra Bakti Ngada Gelar Pengabdian Masyarakat di Malanuza. Pos-Kupang.com,16 (2). Diunduh dari 
https://kupang.tribunnews.com/2019/11/03/dosen-prodi-pjkr-stkip-citra-bakti-ngadagelar-pengabdian-masyarakat-di-malanuza

Moses, Adeputra. (2019, 9 Juli). Dosen PJKR STKIP Citra Bakti adakan Pengabdian Masyarakat. ekorantt.com,15(1).Diunduh dari https://ekorantt.com/2019/07/09/dosen-pjkr-stkip-citra-bakti-adakan-pengabdian masyarakat/.

Natal, Y.R. (2018). Manajemen Pembinaan Olahraga Atletik Lari Jarak Jauh 10.000 Meter Pada Pasi Provinsi NTT : Jurnal IImiah Pendidikan Citra Bakti. Volume 5 Nomor 1, Halaman 15-23.

Natal,Y.R. (2019). Kebijakan Pemerintah Tentang Penyediaan Sarana Dan Prasarana Olahraga Pendidikan Di SMP Negeri Se-Kecamatan Bajawa : Jurnal IMEDTECH : Instructional Media,Design And Technology spesial issue. Volume 3 Nomor 1, 185199.

PP.PBVSI, (2017). Peraturan Permainan Bola Voli. Jakarta :PP. PBVSI.

Sumaryanto, (2012). Perspektif Filsafat Olahraga Dalam Mewujudkan Masyarakat Yang Sehat. Yogyakarta : Medikora.

Sunardi, Joko dkk. (2012). Pelatihan Wasit Bola Voli Kabupaten Sleman : Laporan Kegiatan PPM. Yogyakarta : LPPM UNY. 